\title{
A Study of the Distribution between Each Province about China Style Innovation
}

\author{
Takanori Minamikawa \\ Research Division, Economic Research Institute for Northeast Asia, Niigata, Japan \\ Email: minamikawa.takanori.60@erina.or.jp
}

How to cite this paper: Minamikawa, T. (2019) A Study of the Distribution between Each Province about China Style Innovation. Theoretical Economics Letters, 9, 1316-1329.

https://doi.org/10.4236/tel.2019.95085

Received: April 28, 2019

Accepted: May 28, 2019

Published: May 31, 2019

Copyright (c) 2019 by author(s) and Scientific Research Publishing Inc. This work is licensed under the Creative Commons Attribution International License (CC BY 4.0).

http://creativecommons.org/licenses/by/4.0/

(c) (i) Open Access

\begin{abstract}
Since publishing its "National Mid- and Long-Term Science Technology Development Plan" in 2006, China has continued to publicly recognize the importance of innovation. The present study aims to both index and evaluate the progress of innovation within all the provinces of China, including provincial cities and autonomous regions (province hereafter). Innovation, as defined in this study, encompassed not only the development of previously unseen cutting-edge technology, but also the technical improvement or introduction of methods which lead to increased production and market expansion. This paper examines the distribution of innovation achieved in Chinese provinces utilizing the Aggregate Demand-Aggregate Supply model, and moreover, considers the intensive area of innovation occurrence. In existing literature, such innovation is recognized as the China Style Innovation; however, as the methodology of this study provides information relative to effective innovation, meaning the innovation with market expansion for objective area, it can be applied to nations other than China.
\end{abstract}

\section{Keywords}

AD-AS Model, Chinese Economy, Innovation

\section{Introduction}

\subsection{Innovation in China}

Since China published its "National Mid- and Long-Term Science Technology Development Plan" in 2006, the nation has sought ways to achieve sustained economic growth through innovation. Thereafter, China has recognized the importance of innovation, citing it in the 12th Five-Year Plan, and "Made in China 2025" policy. Until 2013, China had achieved super-high-speed economic growth by way of large-scale investment. As a result of the huge input on the 
supply side, excess productivity has occurred; furthermore, the excess productivity becomes restriction for the production in the areas, where old industry occupied a lot of market share. Since 2013, however, China has been clearly conscious of the "New Normal", and requires an improvement in productivity which will ultimately contribute to economic growth. In order to quantify how the provinces (including provincial class cities and autonomous regions; province as follow) have achieved such innovation, this paper introduces two indices to reflect the current status of innovation in China, and to evaluate them.

Within this paper, I define innovation as "not only the creation of previously unseen cutting-edge technology, but also the technical improvement or introduction of methods which contribute to an increase in market expansion". In other words, the improvement of production conditions, which respond to the requirements of the potential market, stimulates aggregate demand in the market and results in market expansion. Such innovation is consistent with the "Niche creation", which is described in [1] as the improvement of production which responds to potential market requirements. In order to index this class of innovation, I apply the estimation of [2]'s model for all provinces. [2] model is an Aggregate Demand (AD as follow)-Aggregate Supply (AS as follows) model which makes the indexation of the AS shock with the shift in AD shock possible to derive. Moreover, this type of AS shock is consistent with the concept of innovation defined within this study. I derive two indices to capture the characteristics of AS shock for all provinces, after which I evaluate the current status of innovation in each to determine its level of success.

\subsection{Literature of Innovation in China}

Various studies on Chinese innovation seek to examine the relationships between innovation and economic growth, with patents, Research and Development investment ( $\mathrm{R} \& \mathrm{D}$ as follows) or Total Factor Productivity (TFP as follows) used as proxy variables of innovation. [3] examines the interaction relationship among privatization of state-owned enterprises, intellectual property protection and innovation by using the Difference in Difference method, arguing that the privatization of state-owned enterprises significantly increases patent numbers, and the protection of intellectual property policy mitigates the advantages of private sectors. [4] estimates the dynamic panel data model with energy consumption and TFP, a proxy of innovation, confirming that innovation and energy consumption has a correlation in the short-term, yet it is unclear whether innovation leads to a long-term decrease in energy consumption. Using import and patent data to investigate the relationship between competitiveness of the import industry sector and innovation, [5] concludes that competitiveness boosts progress in innovation. [6] assesses the relationship between Foreign Direct Investment (FDI hereafter) and R \& D in addition to FDI and patent by using panel data for 27 provinces and argue that the effect from FDI on innovation differs among regions. [7] estimated Vector Auto-Regressive (VAR 
as follows) model for R \& D, patent and economic growth to examine their interaction. Results show $\mathrm{R} \& \mathrm{D}$ has significantly positive effects on patents, yet despite the achievements gained from technological effort, patents themselves have little impact on economic growth. Although previous literature on innovation in China uses proxy variables for innovation, there is no consensus as to whether $\mathrm{R}$ \& D or patents are directly responsible for the improvement of productivity or innovation. In fact, [7] stated that R \& D and patents have an insignificant effect on economic growth.

Although existing literatures of Innovation in China study the proxy variables of innovation and interested economic variables, such as economic growth, energy consumption and policy dummies, the proxy variables do not reflect the strength of innovation. As suggested above, R \& D or patents denote the motivations of innovation, however, they do not necessarily lead to positive change in economic growth or improvement of productivity. The present paper considers this point, and I recognize the AS shock of AD-AS model as the improvement in productivity. Thus it is different from existing literatures. Furthermore the China style innovation is the improvement in productivity, which is consistent with potential demand in the market. This improvement results in market expansion. The characteristics of this paper are these types of indexation of innovation, which means that the strength of China style innovation is indicated with the correlation between AD shock and AS shock. The index can be calculated with the model explained in [2]. [2] model assumes a correlation between AD shock and AS shock, and I recognize the AS shock in this model as an innovation index. [2] model is based on [8]'s AD-AS model, a structural VAR model which is framed by production and price variables. The long-term restriction of [9], namely the neutrality of production to $\mathrm{AD}$ shock in the long-term, is used to identify the model. Although the [9] assume noncorrelation between AD shock and AS shock, [2] model allows for a correlation between production and price. Furthermore, [2] model is able to extract information about causality from one structural shock to another. This paper assumes causality from AS shock to AD shock and executes the estimation of [2] model.

Positive AS shock expresses the increase in production under constant conditions, which is consistent with technological improvement or the introduction of new methods of production. The assumption of causality from AS shock to AD shock means that the positive AS shock induces positive AD shock, which brings a shift in the $\mathrm{AD}$ curve to the right. This situation can be explained by improvement in technology or the creation of new production processes that expand market demand while inducing a larger increase of income that is experienced with the occurrence of AS shock only. Such improvement and market stimulation are defined as innovation in this paper, and I examine the degree of innovation progress for each province, employing the values of AS shock and the causality coefficients from AS shock to AD shock. This article is organized as follows. Section 2 shows the methodology and data used for estimation. Section 3 indicates the estimation result, and Section 4 draws conclusions. 


\section{Data and Method}

Two variables, production and price, are used to examine the current status of innovation in China. Both variables, calculated with GDP and CPI data published in the website of National Bureau of Statistics of China, are recognized as level variables and used for model estimation ${ }^{1}$. The variables are normalized, with the values for 1995 adjusted to 100 for each province. Citing a lack of data, Tibet is excluded as an object of examination, therefore, 30 provinces are verified in total. To estimate the model for time-series data, such as VAR model, it is necessary to clarify the stationarity of data for estimation. Generally speaking, the reasons behind fluctuation in stationarity include both probabilistic and non-probabilistic factors. As for probabilistic factors, cases exist where the Data Generating Process (DGP) follow the process with probabilistic trend, such as unit root, which refers to a time-series process in which the mean value or variance deviates from the constant level. On the other hand, a non-probabilistic factor explains the process which follows with structural breaks. In the case that DGP follows a non-stationary process due to the probabilistic factor, the estimation result is suggested to become spurious regression. From the behavior of the data, both of the level variables are considered to have a higher order of integration than just one, which is unit root process, while first order differenced process is thought to be following unit root or long memory process. Furthermore, second order differenced process behaves as like stationary process around zero value. From the above, first order differenced variables of production and price are used for estimation. Before executing the estimation, it is necessary to confirm whether the variables are unit root process or long memory stationary process.

At first, the unit root tests are applied to both the production and price data for each province. Even if the data follows unit root process, the estimation results of their regression results are known not to be spurious regression when the regression is consistent with a cointegration relationship. In the case that first order differenced variables of both production and price follow stationary process, the spurious regression is not expected to occur, therefore, data will be used for estimation of VAR model. If the two variables are consistent with unit root process according to the statistical test and the relationship of regression is thought to display a cointegration relationship, the first order differenced processes are used for estimation. If only one variable follows unit root process, the same verification is executed for second order differenced processes.

After ensuring the stationarity of data, the AD-AS model explained in [2] is estimated. That model is based on the work proposed by [8], and to which the long-run restriction for identification of [9] is introduced. The model is:

$$
\begin{aligned}
& y^{s}=\mathrm{E}_{t-1}\left(y_{t}\right)+\alpha\left(p_{t}-\mathrm{E}_{t-1}\left(p_{t}\right)\right)+\varepsilon_{t},(\alpha>0) \\
& y_{t}^{d}+p_{t}=\mathrm{E}_{t-1}\left(y_{t}\right)+p_{t}+\eta_{t} \\
& y_{t}^{d}=y_{t}^{s}
\end{aligned}
$$

${ }^{1} \mathrm{~A}$ statistical summary of data is shown in Table 1 and Table 2. 
Table 1. Statistic summary of level data of production.

\begin{tabular}{|c|c|c|c|c|c|}
\hline \multicolumn{6}{|c|}{$\operatorname{Prod}(1995=100)$} \\
\hline & N. obs & $\min$ & $\max$ & mean & sd \\
\hline Beijing & 23 & 100 & 1133 & 492 & 330 \\
\hline Tianjin & 23 & 100 & 1316 & 566 & 428 \\
\hline Hebei & 23 & 100 & 793 & 401 & 239 \\
\hline Shanxi & 23 & 100 & 926 & 437 & 276 \\
\hline Neimenggu & 23 & 100 & 1370 & 647 & 494 \\
\hline Liaoning & 23 & 100 & 719 & 356 & 217 \\
\hline Jilin & 23 & 100 & 870 & 426 & 285 \\
\hline Heilongjiang & 23 & 100 & 529 & 301 & 156 \\
\hline Shanghai & 23 & 100 & 760 & 374 & 210 \\
\hline Jiangsu & 23 & 100 & 1082 & 452 & 316 \\
\hline Zhejiang & 23 & 100 & 968 & 438 & 281 \\
\hline Anhui & 23 & 100 & 983 & 401 & 283 \\
\hline Fujian & 23 & 100 & 1059 & 432 & 298 \\
\hline Jiangxi & 23 & 100 & 1125 & 470 & 338 \\
\hline Shandong & 23 & 100 & 958 & 435 & 289 \\
\hline Henan & 23 & 100 & 954 & 422 & 277 \\
\hline Hubei & 23 & 100 & 1077 & 437 & 318 \\
\hline Hunan & 23 & 100 & 1002 & 418 & 300 \\
\hline Guangdong & 23 & 100 & 1056 & 463 & 302 \\
\hline Guangxi & 23 & 100 & 853 & 384 & 264 \\
\hline Hainan & 23 & 100 & 830 & 360 & 239 \\
\hline Chongqing & 23 & 100 & 1202 & 456 & 347 \\
\hline Sichuan & 23 & 100 & 919 & 383 & 263 \\
\hline Guizhou & 23 & 100 & 1353 & 462 & 378 \\
\hline Yunnan & 23 & 100 & 833 & 355 & 232 \\
\hline Shaanxi & 23 & 100 & 1366 & 543 & 419 \\
\hline Gansu & 23 & 100 & 815 & 405 & 249 \\
\hline Qinghai & 23 & 99 & 810 & 380 & 257 \\
\hline Ningxia & 23 & 100 & 1224 & 507 & 379 \\
\hline Xinjiang & 23 & 100 & 795 & 364 & 231 \\
\hline All & 690 & 99 & 1370 & 432 & 312 \\
\hline
\end{tabular}

Calculated by author.

$y^{s}$ denotes supply quantity, $y^{d}$ means demand quantity, $p$ is price level, $\mathrm{E}_{t-1}$ indicates the expectation value in $t-1$, and $y$ is the equilibrium quantity, with $\alpha$ the parameter. $\mathrm{E}_{t-1}$ value is constructed by information about past market status, therefore, the model is shown as below. 
Table 2. Statistic summary of level data of price.

\begin{tabular}{|c|c|c|c|c|c|}
\hline \multicolumn{6}{|c|}{ Price $(1995=100)$} \\
\hline & N. obs & $\min$ & $\max$ & mean & sd \\
\hline Beijing & 23 & 100 & 172 & 138 & 19 \\
\hline Tianjin & 23 & 100 & 160 & 126 & 18 \\
\hline Hebei & 23 & 100 & 158 & 125 & 19 \\
\hline Shanxi & 23 & 100 & 165 & 131 & 21 \\
\hline Neimenggu & 23 & 100 & 168 & 132 & 21 \\
\hline Liaoning & 23 & 100 & 155 & 124 & 17 \\
\hline Jilin & 23 & 100 & 159 & 125 & 19 \\
\hline Heilongjiang & 23 & 100 & 157 & 125 & 19 \\
\hline Shanghai & 23 & 100 & 168 & 131 & 19 \\
\hline Jiangsu & 23 & 100 & 162 & 127 & 19 \\
\hline Zhejiang & 23 & 100 & 157 & 125 & 17 \\
\hline Anhui & 23 & 100 & 159 & 127 & 19 \\
\hline Fujian & 23 & 100 & 152 & 122 & 16 \\
\hline Jiangxi & 23 & 100 & 161 & 127 & 18 \\
\hline Shandong & 23 & 100 & 161 & 128 & 18 \\
\hline Henan & 23 & 100 & 165 & 129 & 21 \\
\hline Hubei & 23 & 100 & 165 & 128 & 21 \\
\hline Hunan & 23 & 100 & 168 & 132 & 22 \\
\hline Guangdong & 23 & 100 & 149 & 120 & 15 \\
\hline Guangxi & 23 & 100 & 153 & 120 & 18 \\
\hline Hainan & 23 & 100 & 154 & 118 & 19 \\
\hline Chongqing & 23 & 100 & 151 & 122 & 16 \\
\hline Sichuan & 23 & 100 & 174 & 135 & 23 \\
\hline Guizhou & 23 & 100 & 167 & 131 & 21 \\
\hline Yunnan & 23 & 100 & 171 & 133 & 22 \\
\hline Shaanxi & 23 & 100 & 164 & 129 & 20 \\
\hline Gansu & 23 & 100 & 173 & 133 & 24 \\
\hline Qinghai & 23 & 100 & 206 & 148 & 34 \\
\hline Ningxia & 23 & 100 & 172 & 131 & 24 \\
\hline Xinjiang & 23 & 100 & 176 & 134 & 24 \\
\hline All & 690 & 100 & 206 & 129 & 21 \\
\hline
\end{tabular}

Calculated by author.

$$
\begin{gathered}
\mathrm{E}_{t-1}\left(y_{t}\right)=A(L) y_{t}, \quad \mathrm{E}_{t-1}\left(p_{t}\right)=A(L) p_{t} \\
A(L)=\left[\begin{array}{ll}
a_{11}(L) & a_{12}(L) \\
a_{21}(L) & a_{22}(L)
\end{array}\right] \text { can be expressed with lag operator } L . \text { This econo- }
\end{gathered}
$$


my is described with reduced form VAR model as below.

$$
\left[\begin{array}{c}
y_{t} \\
p_{t}
\end{array}\right]=\left[\begin{array}{ll}
a_{11}(L) & a_{12}(L) \\
a_{21}(L) & a_{22}(L)
\end{array}\right]\left[\begin{array}{l}
y_{t} \\
p_{t}
\end{array}\right]+\left[\begin{array}{l}
e_{y t} \\
e_{p t}
\end{array}\right]
$$

$e_{y t}$ and $e_{p t}$ are error terms of reduced form VAR model. $C$ matrix is introduced, which expresses the relationship between the error term of reduced form and structural shock $\varepsilon_{t}$ and $\eta_{t}$.

$$
\begin{aligned}
& \boldsymbol{e}_{t}=\boldsymbol{C} \boldsymbol{\epsilon}_{t} \\
& {\left[\begin{array}{l}
e_{y t} \\
e_{p t}
\end{array}\right]=\left[\begin{array}{ll}
c_{11} & c_{12} \\
c_{21} & c_{22}
\end{array}\right]\left[\begin{array}{l}
\varepsilon_{t} \\
\eta_{t}
\end{array}\right]}
\end{aligned}
$$

The model can be displayed as matrix form as below.

$$
\begin{aligned}
{\left[\begin{array}{l}
y_{t} \\
p_{t}
\end{array}\right] } & =\left[\begin{array}{l}
\mathrm{E}_{t-1} y_{t} \\
\mathrm{E}_{t-1} p_{t}
\end{array}\right]+\left[\begin{array}{cc}
\frac{1}{1+\alpha} & \frac{\alpha}{1+\alpha} \\
\frac{-1}{1+\alpha} & \frac{1}{1+\alpha}
\end{array}\right]\left[\begin{array}{l}
\varepsilon_{t} \\
\eta_{t}
\end{array}\right] \\
& =\left[\begin{array}{ll}
a_{11}(L) & a_{12}(L) \\
a_{21}(L) & a_{22}(L)
\end{array}\right]\left[\begin{array}{l}
y_{t} \\
p_{t}
\end{array}\right]+\left[\begin{array}{cc}
\frac{1}{1+\alpha} & \frac{\alpha}{1+\alpha} \\
\frac{-1}{1+\alpha} & \frac{1}{1+\alpha}
\end{array}\right]\left[\begin{array}{l}
\varepsilon_{t} \\
\eta_{t}
\end{array}\right]
\end{aligned}
$$

Therefore, the coefficients of reduced form VAR and Structural VAR are shown below,

$$
\begin{aligned}
& {\left[\begin{array}{ll}
c_{11} & c_{12} \\
c_{21} & c_{22}
\end{array}\right]\left[\begin{array}{ll}
\sigma_{\varepsilon}^{2} & \sigma_{\varepsilon \eta} \\
\sigma_{\varepsilon \eta} & \sigma_{\eta}^{2}
\end{array}\right]\left[\begin{array}{ll}
c_{11} & c_{21} \\
c_{12} & c_{22}
\end{array}\right]=\left[\begin{array}{cc}
\frac{1}{1+\alpha} & \frac{\alpha}{1+\alpha} \\
\frac{-1}{1+\alpha} & \frac{1}{1+\alpha}
\end{array}\right]\left[\begin{array}{cc}
\sigma_{\varepsilon}^{2} & \sigma_{\varepsilon \eta} \\
\sigma_{\varepsilon \eta} & \sigma_{\eta}^{2}
\end{array}\right]\left[\begin{array}{cc}
\frac{1}{1+\alpha} & \frac{-1}{1+\alpha} \\
\frac{\alpha}{1+\alpha} & \frac{1}{1+\alpha}
\end{array}\right]} \\
& c_{11}=\alpha c_{12}, \quad c_{11}=-c_{21}, \quad c_{11}=c_{22} \text { can be derived. }
\end{aligned}
$$

The long-run restriction for identification is displayed below.

$$
\begin{aligned}
& {[\boldsymbol{I}-\boldsymbol{A}(1)] \boldsymbol{y}_{t}=\boldsymbol{e}_{t}} \\
& \boldsymbol{y}_{t}=[\boldsymbol{I}-\boldsymbol{A}(1)]^{-1} \boldsymbol{e}_{t}
\end{aligned}
$$

The cumulative impulse response functions are expressed with matrix $C$,

$$
\begin{aligned}
\boldsymbol{y}_{\boldsymbol{t}} & =[\boldsymbol{I}-\boldsymbol{A}(1)]^{-1} \boldsymbol{C}_{t} \\
& =\left[\begin{array}{cc}
1-a_{11}(1) & -a_{12}(1) \\
-a_{21}(1) & 1-a_{22}(1)
\end{array}\right]^{-1}\left[\begin{array}{c}
c_{11} \varepsilon_{t}+c_{12} \eta_{t} \\
c_{21} \varepsilon_{t}+c_{22} \eta_{t}
\end{array}\right] \\
& \left.=\frac{a_{12}(1) a_{21}(1)}{\left[1-a_{11}(1)\right]\left[1-a_{22}(1)\right.}\right]\left[\begin{array}{cc}
1-a_{22}(1) & a_{12}(1) \\
a_{21}(1) & 1-a_{11}(1)
\end{array}\right]\left[\begin{array}{c}
c_{11} \varepsilon_{t}+c_{12} \eta_{t} \\
c_{21} \varepsilon_{t}+c_{22} \eta_{t}
\end{array}\right]
\end{aligned}
$$

and the above relationship can be reduced. Suppose $B=\frac{a_{12}(1) a_{21}(1)}{\left[1-a_{11}(1)\right]\left[1-a_{22}(1)\right]}$, and the response of production for AD shock, which is the object of long-run restriction for identification, is shown as, 


$$
\begin{aligned}
y_{t} & =B\left[1-a_{22}(1)\right]\left(c_{11} \varepsilon_{t}+c_{12} \eta\right)+B a_{12}(1)\left(c_{21} \varepsilon_{t}+c_{22} \eta_{t}\right) \\
& =B\left[\left(1-a_{12}(1)\right) c_{12}+a_{12}(1) c_{22}\right] \eta_{t}+B\left[\left(1-a_{22}(1)\right) c_{11}+a_{12}(1) c_{21}\right] \varepsilon_{t}
\end{aligned}
$$

then the neutrality of production to $\mathrm{AD}$ shock is

$$
B\left[\left(1-a_{12}(1)\right) c_{12}+a_{12}(1) c_{22}\right]=0 \text {. }
$$

[2]'s model allows for not only the correlation between structural shocks, but also the causality relationship of structural shock as shown below.

$$
\eta_{t}=\rho \varepsilon_{t}+v_{t}
$$

This assumes the causality from AS shock to AD shock. $v_{t} \sim N\left(\mathbf{0}, \sigma_{v}^{2}\right)$ denotes the white noise, which does not correlate with $\varepsilon_{t}$. This equation is written in matrix form as below.

$$
\left[\begin{array}{c}
\varepsilon_{t} \\
\eta_{t}
\end{array}\right]=\left[\begin{array}{c}
\varepsilon_{t} \\
\rho \varepsilon_{t}+v_{t}
\end{array}\right]=\left[\begin{array}{ll}
1 & 0 \\
\rho & 1
\end{array}\right]\left[\begin{array}{l}
\varepsilon_{t} \\
v_{t}
\end{array}\right]
$$

The values of variance-covariance matrix of error terms of reduced form VAR lead,

$$
\mathrm{E}\left(\boldsymbol{e}_{t} \boldsymbol{e}_{t}^{\prime}\right)=\left[\begin{array}{cc}
\frac{1}{1+\alpha} & \frac{\alpha}{1+\alpha} \\
\frac{-1}{1+\alpha} & \frac{1}{1+\alpha}
\end{array}\right]\left[\begin{array}{cc}
1 & 0 \\
\rho & 1
\end{array}\right]\left[\begin{array}{cc}
\sigma_{\varepsilon}^{2} & 0 \\
0 & \sigma_{v}^{2}
\end{array}\right]\left[\begin{array}{cc}
1 & \rho \\
0 & 1
\end{array}\right]\left[\begin{array}{cc}
\frac{1}{1+\alpha} & \frac{-1}{1+\alpha} \\
\frac{\alpha}{1+\alpha} & \frac{1}{1+\alpha}
\end{array}\right]
$$

furthermore, the strength of causality of AS shock to AD shock can be expressed with $\rho$ coefficient. Since the coefficient of first order difference variables model and second order differenced variables model are the same because of the model structure, the causality coefficients $\rho$ are indiscriminately verified for all provinces.

\section{Empirical Results}

With Tibet excluded from verification, the stationarity of data was examined for 30 provinces. The behaviors of all first order differenced variables are recognized as the processes with non-zero intercepts, which are consistent with non-zero real GDP growth or inflation rates. Given the possibility of non-zero constant terms, [10]'s unit root test was executed, with the results of statistical testing shown in Table 3. The table shows the null hypothesis that "process is unit root process" is rejected in 18 provinces for both variables. Liaoning province showed the null hypothesis is rejected for neither variable, therefore, VAR residuals are tested using the $5 \%$ critical point outlined in [11]'s unit root. For the remaining provinces, second order differenced variables were tested. The behavior of second order differenced data is considered to follow stationary process around zero, therefore, the Augmented Dickey Fuller test was applied. As results of the statistical tests show, to estimate the model, first order differenced variables were used for 19 provinces, while second order differenced variables were applied to 11 provinces.

According to Table 4, most of the $\rho$ coefficients show high causality, with the exception of Hebei, Zhejiang and Ningxia, where causality is lower. The 
Table 3. Unit-Root TEST.

\begin{tabular}{|c|c|c|c|c|c|c|}
\hline & $\Delta y_{t}$ & $\Delta p_{t}$ & $\Delta e_{y t}$ & $\Delta e_{p t}$ & $\Delta^{2} y$ & $\Delta^{2} p$ \\
\hline Beijing & 1 & 1 & - & - & - & - \\
\hline Tianjin & 1 & 1 & - & - & - & - \\
\hline Hebei & 1 & 1 & - & - & - & - \\
\hline Shanxi & 1 & 1 & - & - & - & - \\
\hline Neimenggu & 0 & 1 & - & - & 1 & 1 \\
\hline Liaoning & 0 & 0 & 1 & 1 & 1 & 1 \\
\hline Jilin & 1 & 0 & - & - & 1 & 1 \\
\hline Heilongjiang & 1 & 0 & - & - & 1 & 1 \\
\hline Shanghai & 0 & 1 & - & - & 1 & 1 \\
\hline Jiangsu & 1 & 1 & - & - & - & - \\
\hline Zhejiang & 1 & 0 & - & - & 1 & 1 \\
\hline Anhui & 1 & 1 & - & - & - & - \\
\hline Fujian & 1 & 1 & - & - & - & - \\
\hline Jiangxi & 1 & 1 & - & - & - & - \\
\hline Shandong & 1 & 1 & - & - & - & - \\
\hline Henan & 1 & 1 & - & - & - & - \\
\hline Hubei & 1 & 1 & - & - & - & - \\
\hline Hunan & 1 & 0 & - & - & 1 & 1 \\
\hline Guangdong & 1 & 0 & - & - & 1 & 1 \\
\hline Guangxi & 1 & 0 & - & - & 1 & 1 \\
\hline Hainan & 1 & 1 & - & - & - & - \\
\hline Chongqing & 1 & 1 & - & - & - & - \\
\hline Sichuan & 1 & 0 & - & - & 1 & 1 \\
\hline Guizhou & 1 & 0 & - & - & 1 & 1 \\
\hline Yunnan & 1 & 1 & - & - & - & - \\
\hline Shaanxi & 1 & 1 & - & - & - & - \\
\hline Gansu & 1 & 1 & - & - & - & - \\
\hline Qinghai & 1 & 1 & - & - & - & - \\
\hline Ningxia & 1 & 1 & - & - & - & - \\
\hline Xinjiang & 0 & 1 & - & - & 1 & 1 \\
\hline
\end{tabular}

1 denotes that the null hypothesis is rejected at $5 \%$ significant level, 0 denotes otherwise.

provinces, of which the value of causality coefficients $\rho$ are ranked in the top $25 \%$, are Heilongjiang, Anhui, Hubei, Hunan, Chongqing, Sichuan, Guizhou and Yunnan. We learn that AS shock causes strong AD shock, and, technical improvement or introduction of new production methods leads to potential market demand. As a result, AS shock expanded production quantity more than 
it did in cases without the causality effect.

The changes in AS shock are shown in Figure 1. Changes are expressed as minimum points, maximum points, quartile points and medians, and indicates that the changes in AS shock of each province display the same trend. Except for the drastic decline in Liaoning province in 2016, changes in AS shock fluctuate across a narrow range, and all provinces were severely impacted by the Global Recession of 2009.

The geometrical distribution of $\rho$ is shown in Figure 2. Except for Heilongjiang, the provinces whose $\rho$ values rank in the upper quartile are concentrated in inland China. On the other hand, the provinces with $\rho$ values ranked in the bottom $25 \%$ represent a portion of the Jing-Jin-Ji economic area or advanced economy area, such as Beijing, Hebei, Zhejiang and Guangdong. The definition of innovation applied to this study is concerned with the relationship between the supply side and market systems, and not whether the target area has high aggregate demand. Therefore, the AS shocks do not correspond to short-term economic growth, and $\rho$ values show whether the catalyst of innovation in a province is AS shock accompanied with AD shock, which results in to technological improvement or the introduction of new production methods in response to potential requirements within the market.

Although the estimated values of $\rho$, see Figure 1, suggest a geometrical concentration, it does not necessarily correspond to the country's wide-area development policies, such as China Western Development or Rise of Central China. Instead, provincial domestic factors may be a more likely reason.

To confirm the robustness of the results, the same estimation is executed with Retail Price Index (RPI as follow) of China, shown in Table 5. Similar results are shown with RPI data for Price variables as CPI data. 5 of the 8 provinces show both results as -1 (denotes that the value is less than lower $25 \%$ ), and 7 of the 8

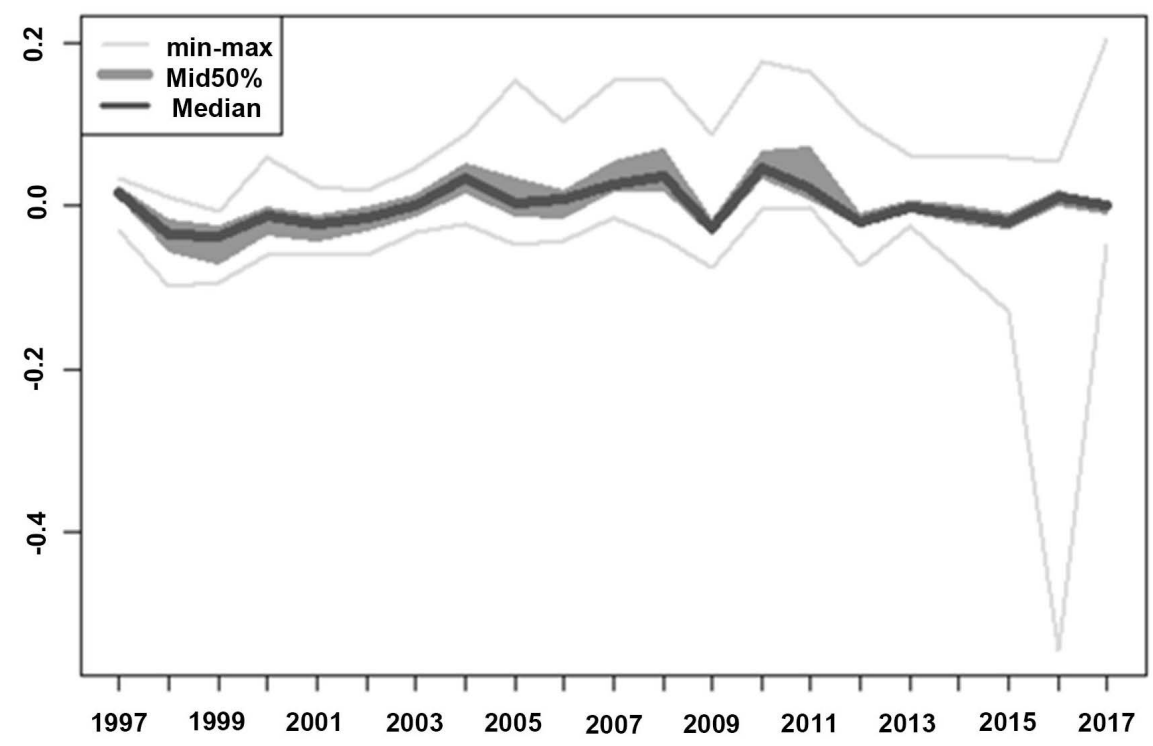

Figure 1. $\eta_{t}$ series (1997-2017). Created by author. 


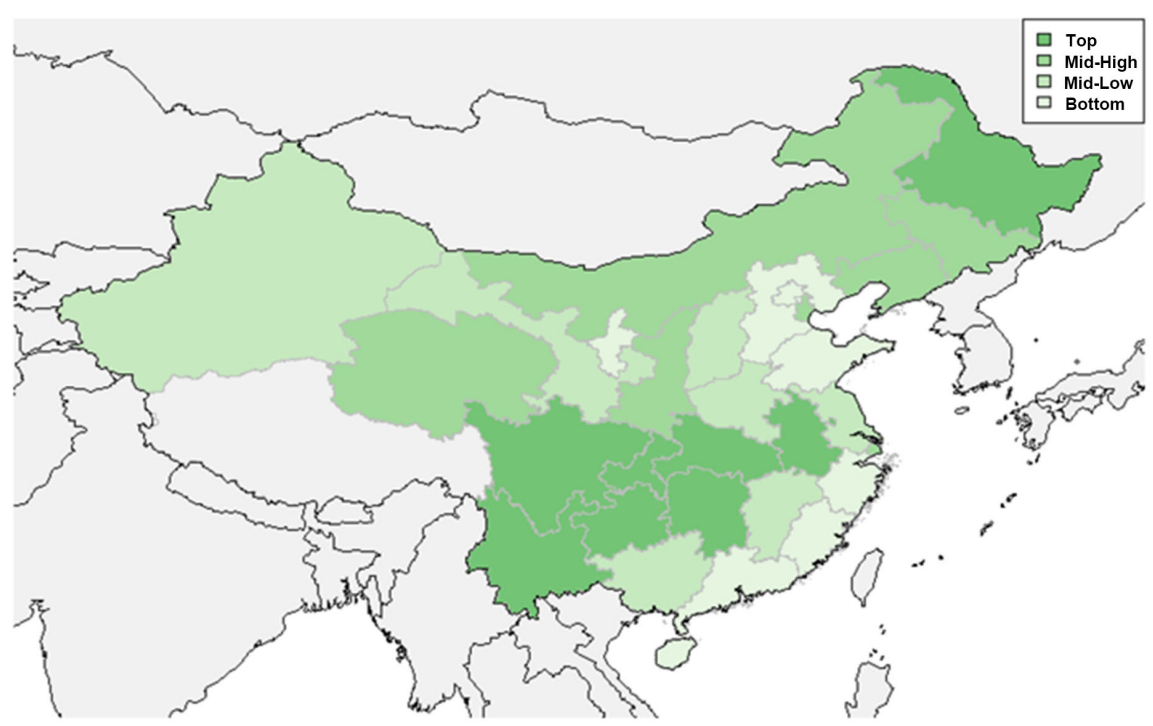

Figure 2. Distribution of the estimated values of $\rho$. Created by author.

Table 4. Estimated values of $\rho$.

\begin{tabular}{ccccccc}
\hline Beijing & Tianjin & Hebei & Shanxi & Neimenggu & Liaoning & Jilin \\
\hline 0.644 & 1.047 & 0.471 & 0.820 & 1.002 & 1.022 & 1.086 \\
Heilongjiang & Shanghai & Jiangsu & Zhejiang & Anhui & Fujian & Jiangxi \\
1.288 & 0.914 & 0.901 & 0.368 & 1.282 & 0.730 & 0.886 \\
Shandong & Henan & Hubei & Guangdong & Guangxi & Hunan & Hainan \\
0.751 & 0.868 & 1.236 & 0.804 & 0.835 & 1.683 & 0.700 \\
Chongqing & Sichuan & Guizhou & Yunnan & Shaanxi & Gansu & Qinghai \\
1.300 & 1.248 & 1.434 & 1.254 & 1.058 & 0.832 & 1.206 \\
Ningxia & Xinjiang & & & & & \\
0.437 & 0.907 & & & & & \\
\hline
\end{tabular}

Calculated by author

provinces show both results as 1 (denotes that the value is higher than upper $25 \%)$. Furthermore the geometric concentrations of Inland area of China (Chongqing, Sichuan, Guizhou, Hubei, Anhui, and Yunnan) is shown in the estimation results with RPI data.

\section{Conclusions}

This paper defines innovation as not only the discovery of imaginative technology, but also the improvement of the supply side in a broader sense. Most importantly, this definition states that improvement is consistent with the market requirements. This innovation is conformable with the definition pointed out in existing literature; in fact, some cases highlight achievements in innovation which occurred in response to potential requirements of market, such as shared bicycle industry and online payments. As results show from verification of the 
Table 5. Comparison of result between using CPI and using RPI.

\begin{tabular}{|c|c|c|}
\hline & CPI & RPI \\
\hline Beijing & -1 & -1 \\
\hline Tianjin & 0 & 0 \\
\hline Hebei & -1 & -1 \\
\hline Shanxi & 0 & 0 \\
\hline Neimenggu & 0 & 0 \\
\hline Liaoning & 0 & 0 \\
\hline Jilin & 0 & 0 \\
\hline Heilongjiang & 1 & 1 \\
\hline Shanghai & 0 & 0 \\
\hline Jiangsu & 0 & -1 \\
\hline Zhejiang & -1 & -1 \\
\hline Anhui & 1 & 1 \\
\hline Fujian & -1 & 0 \\
\hline Jiangxi & 0 & 0 \\
\hline Shandong & -1 & -1 \\
\hline Henan & 0 & 0 \\
\hline Hubei & 1 & 1 \\
\hline Guangdong & -1 & 1 \\
\hline Guangxi & 0 & -1 \\
\hline Hunan & 1 & -1 \\
\hline Hainan & -1 & 0 \\
\hline Chongqing & 1 & 1 \\
\hline Sichuan & 1 & 1 \\
\hline Guizhou & 1 & 1 \\
\hline Yunnan & 1 & 1 \\
\hline Shaanxi & 0 & 0 \\
\hline Gansu & 0 & 0 \\
\hline Qinghai & 0 & 0 \\
\hline Ningxia & -1 & -1 \\
\hline Xinjiang & 0 & 0 \\
\hline
\end{tabular}

When $\rho$ value is higher than upper $25 \%$, the value is 1 , and less than lower $25 \%$, the value is -1 .

degree of innovation in each province using AD-AS model, although Heilongjiang province can be considered as a single innovative province, other more innovative provinces are concentrated in a region of inland China. In these provinces, positive AS shock brings an expansion of aggregate demand to the market and contributes to economic growth. Furthermore, it is shown that ad- 
vanced economic areas are not required to achieve innovation. The above description does not contradict the definition of innovation offered in this paper. In an area where explicit aggregate demand exists, the motivation to explore potential demand is possibly less on the supply side.

Considering the geometric distribution of estimated values of $\rho$ coefficient, interaction effects might exist among province, because some high values provinces are concentrated, while other lower values provinces are adjacent, such as Hebei, Beijing and Shandong, or Zhejiang, Fujian and Guangdong. It is considered that innovation is not specific to each province and that contributing factors may include interaction effects between neighboring provinces, or the possibility of AS shock spreading from one province to adjacent provinces. Although the distribution shows geometric characteristics, it does not correspond with the country's wide-area development policies, such as China Western Development or Rise of Central China. Therefore, it is probable that the high $\rho$ values reflect not only Central Government policy, but also improvement in the supply side stimulated by provincial government policy, and the economic activities of the private sector.

The effects of interaction will be further investigated in future research. In closing, though the methodology outlined in this paper is used to clarify innovation and the resulting economic growth in China, it can be applied to any other nation or economy that intends to investigate the degree of achievement of innovation corresponding to its market requirements. With the use of only two basic data, such as production and price, this method is considered to be highly feasible.

\section{Conflicts of Interest}

The author declares no conflicts of interest regarding the publication of this paper.

\section{References}

[1] Tetsuya, K. (2019) “Giant Niche” Innovation in China. ERINA REPORT (PLUS), $146,3-8$.

[2] Cover, J.P., Enders, W. and Hueng, C.J. (2006) Using the Aggregate Demand-Aggregate Supply Model to Identify Structural Demand-Side and Supply-Side Shocks: Results Using a Bivariate VAR. Journal of Money, Credit, and Banking, 38, 777-790. https://doi.org/10.1353/mcb.2006.0041

[3] Fang, L. H., Lerner, J. and Wu, C.P. (2017) Intellectual Property Rights Protection, Ownership, and Innovation: Evidence from China. The Review of Financial Studies 30, 2446-2477. https://doi.org/10.1093/rfs/hhx023

[4] Jin, L., Duan, K. and Tang, X. (2018) What Is the Relationship between Technological Innovation and Energy Consumption? Empirical Analysis Based on Provincial Panel Data from China. Sustainability, 10, 145. https://doi.org/10.3390/su10010145

[5] Bombardini, M., Li, B.J. and Wang, R.Y. (2017) Import Competition and Innovation: Evidence from China. Technical Report.

[6] Wei, Y.Q., Liu, X.M., Song, H.Y. and Romilly, P. (2001) Endogenous Innovation 
Growth Theory and Regional Income Convergence in China. Journal of International Development, 13, 153-168. https://doi.org/10.1002/jid.721

[7] Yu, Q.T. and Dong, W.Y. (2018) The Interactive Relationship between Sci-Tech Innovation and Economic Growth: An Empirical Study Based on China Macroeconomic Data. Applied Economics and Finance, 5, 82-88.

https://doi.org/10.11114/aef.v5i3.3180

[8] Lucas Jr., R.E. (1972) Expectations and the Neutrality of Money. Journal of Economic Theory, 4, 103-124. https://doi.org/10.1016/0022-0531(72)90142-1

[9] Blanchard, O.J. and Quah, D. (1989) The Dynamic Effects of Aggregate Demand and Supply Disturbances. The American Economic Review, 79, 655-673.

[10] Elliott, G., Rothenberg, T.J. and Stock, J. (1996) Efficient Tests for an Autoregressive Unit Root. Econometrica, 64, 813-836. https://doi.org/10.2307/2171846

[11] Engle, R.F. and Granger, C.W.J. (1987) Co-Integration and Error Correction: Representation, Estimation, and Testing. Econometrica, 55, 251-276.

https://doi.org/10.2307/1913236 